\title{
Rechtsgeschichte
}

\section{Juan Ferrer}

\section{Una receta para la diversidad}


federale suprema. La Corte proprio sulla base della clausola due process of law contenuta nel XIV emendamento privilegiò, infatti, la protezione del diritto di proprietà e con essa le ragioni degli schiavisti, di chi cioè si considerava espropriato appunto di una sua proprietà.

Anche dopo la guerra civile a fronte di una trasformazione del concetto di cittadinanza il diritto di proprietà continuava quindi ad essere un elemento di controllo che legittimava l'ordine sociale e ne assicurava la conservazione. Alla giurisprudenza delle corti americane fu affidato il compito di tenere insieme diritti di cittadinanza e diritto di proprietà. Ma come sarebbe stato possibile? E come si sarebbe potuto continuare a garantire la tutela del diritto di proprietà senza mettere in gioco l'eventualità di una redistribuzione della ricchezza? Clavero non ci aiuta a trovare delle risposte, ma è chiaro che ora non servono più né Locke né Blackstone né tantomeno si possono sciogliere le contraddizioni costituzionali trovando rifugio nella famiglia, all'ombra della potestà di un padre. Mi sembra cioè che dopo la guerra civile americana il paradigma interpretativo fondato sull'ordine domestico non riesca più ad offrire delle risposte soddisfacenti per comprendere la continuata esclusione delle popolazioni di colore come di altre categorie deboli e che forse vada integrato o sostituito con altre chiavi di lettura che privilegino la dimensione economica e riconoscano la forza costituente di un nuovo potere, quello economico appunto. ${ }^{3} \mathrm{Da}$ un lato, infatti, la giurisprudenza ripensava il diritto di proprietà, il principio di responsabilità civile e di responsabilità oggettiva per adeguarli ai nuovi criteri imposti dalla civiltà industriale e dalle nuove tecnologie, dall'altro ridefiniva il concetto di cittadinanza attraverso parametri di condotta esterna "which every man is presumed and required to know ", ${ }^{4}$ ma che in realtà, non tutti erano effettivamente in grado di conoscere.

Luigi Nuzzo

\section{Una receta para la diversidad*}

Como un mago que explica su truco antes de sacar al conejo de la galera, Daniel Bonilla Maldonado anticipa al lector desde sus primeras páginas cuál es su conclusión, su objetivo y el camino que habrá de recorrer para alcanzarlo. Semejante renuncia al suspenso se traduce en una línea argumental de meridiana claridad. »La Constitución Multicultural « nos acerca una valiosa propuesta de interpretación de la Constitución Colombiana de I99I cuya pretensión es el justo reconocimiento y acomodación de las minorías culturales. Su valor agregado es el poten- cial de validez general de los argumentos para revisar otros textos constitucionales que, como el colombiano, contengan en su interior una irresuelta tensión entre unidad y diversidad cultural.

El primer movimiento del autor es la afirmación de un hecho evidente, la existencia de estados culturalmente diversos y los consecuentes conflictos interculturales que se producen dentro de sus fronteras, cosmovisiones del mundo que chocan entre sí y se mantienen en permanente estado de contradicción. La adjetivación

\footnotetext{
3 Morton J. Horwitz, The Transformation of American Law I870-I960. The Crisis of Legal Orthodoxy, New York I992; cfr. anche Howard Schweber, The Creation of American Common Law I 850-I 880. Technology, Politics and the Construction of Citizenship, New York 2004.

4 Oliver Wendell Holmes, The

응

Common Law (I88I), Boston I963, 259.
}

\author{
* Daniel Bonilla Maldonado, \\ La Constitución Multicultural, \\ Bogotá: Siglo del Hombre \\ Editores 2006, 298 p., \\ ISBN 958-665-084-7
}


de Colombia como exponente paradigmático del conjunto de estados que comparten esas características es un tanto generosa. Lo fue en el momento de su escritura, teniendo en cuenta que otros estados latinoamericanos incluso han incorporado artículos en sus Cartas Magnas escritos en la lengua de otras culturas diferentes a la dominante: »Ama quilla, ama llulla, ama shua « (no ser ocioso, no mentir, no robar) dice el art. 97.20 de la Constitución de Ecuador; y lo es con más fuerza hoy una vez sancionada en Bolivia la Constitución de 2009, algo que naturalmente no podemos achacar al autor pero de lo que el lector debe estar prevenido.

La Constitución colombiana de I99I se ubica en un contexto cuyas coordenadas temporales y espaciales el autor omite considerar pero que conviene tener presentes. En las últimas décadas del siglo xx los estados latinoamericanos comenzaron a incorporar en sus textos constitucionales un lenguaje mucho más sensible a la diversidad cultural, Panamá, Guatemala, Nicaragua, México, Paraguay, Perú, Ecuador, son ejemplos de ello y la lista sigue. Países que además comparten las razones que determinaron la prevalencia de la cultura blanca que enumera Bonilla para Colombia: conquista y colonización española, politicas de evangelización de la Iglesia Católica, uso de instrumentos legales y jurídicos para desestimular las tradiciones opuestas. Este conjunto de similitudes es la llave que nos autoriza a proponer, como ya hemos hecho, la validez general de los argumentos contenidos en »La Constitución Multicultural «, al menos para el territorio latinoamericano.

El marco teórico de la obra está construido a partir de un exquisito análisis en clave crítica de los trabajos de quienes sean quizá los más influyentes exponentes de la filosofía política contemporánea en temas referidos a multiculturalis- mo. Para revelar sus límites e inconsistencias, sienta en el banquillo de los acusados nada menos que a Charles Taylor y su multiculturalismo nacido del liberalismo sustantivo, a Will Kymlicka y el liberalismo multicultural, para acabar con James Tully y la reinterpretación del constitucionalismo moderno que propone. Y lo hace con éxito. Desgrana y exprime sus argumentos de modo tal que consigue una conclusión aplastante, la causa del fracaso de estas teorías para reconocer y acomodar la diferencia en los estados multiculturales donde las minorías culturales defienden valores iliberales está precisamente en que ninguno de los tres autores consigue superar el liberalismo, sus ideas están encerradas en los valores liberales fundamentales, democracia y derechos individuales son para ellos un núcleo no negociable en el intercambio cultural. Cada uno de los autores acaba preso de un dilema que Bonilla claramente devela pero que incluso a él le cuesta superar: el compromiso con el liberalismo restringe el espacio para la diferencia cultural; el compromiso con la diferencia cultural puede obligarnos a defender tradiciones que violan algunos de los valores políticos y morales básicos de las sociedades occidentales.

Con tales herramientas teóricas, el autor entra de lleno a considerar la bifronte tensión que motiva su trabajo y cuya superación persigue. Un conflicto entre diversidad y unidad cultural que en un frente opone derechos individuales y diferencia cultural, y en otro, principio de unidad política y derechos de autogobierno de las minorías culturales. Tensión propia de un estado multicultural sensible a la diferencia que en el caso colombiano se reprodujo tanto en la Asamblea Nacional Constituyente de I990, como en la Constitución que resultó de ella en I99I, y en la jurisprudencia de la Corte consti- 
tucional colombiana a partir de su entrada en vigor.

Consciente de la magnitud que tiene una empresa tan vasta como la construcción de una teoría multicultural completa que busque solucionar problemas abstractos de manera abstracta, Bonilla aclara que su objetivo, normativo, es otro, consiste en identificar principios y formular un conjunto de reglas que deberían guiar a las cortes constitucionales en la práctica constitucional, vale decir, en la solución de problemas concretos donde la tensión referida de valores constitucionalmente reconocidos se haga presente. Con este fin, selecciona, describe y analiza una serie de sentencias dictadas por la Corte Constitucional de Colombia entre los años 1992 y 200 I referidas a casos relacionados directamente con cuestiones de diversidad cultural. Fiel a la doble dimensión de la tensión que reconoce, estructura ordenadamente los casos en dos grandes conjuntos a partir de los valores en conflicto, según se trate de contradicción entre derechos individuales y diferencia cultural, o entre el principio de unidad política y el autogobierno de las minorías culturales. En cada uno de los conjuntos dibuja la sinuosa línea jurisprudencial seguida por la Corte, sus opciones teóricas y argumentos jurídicos, sus aciertos y desaciertos, para llegar finalmente a la meta planteada desde el comienzo: la elaboración de una receta para la diversidad, la enunciación de cinco criterios para resolver de manera constitucional y filosóficamente plausible la tensión entre unidad y diversidad cultural: I) El Estado debe ser imparcial - no neutral - frente a todas las culturas; 2) Los derechos de autogobierno de las minorías culturales deben ser maximizados; 3 ) La intervención del Estado debe minimizarse y la intervención de la sociedad civil debe fortalecerse; 4) Los disidentes que existen dentro de las minorías culturales deben tener el derecho de abandonar la comunidad - estrategia de salida -; 5) Las reglas que guían las relaciones entre las minorías culturales y la mayoría deben ser creadas y transformadas a través de diálogos interculturales. Cinco principios que pese a tanto esfuerzo no acaban de quitarse por completo de encima el pesado yugo de la tradición liberal, algunas prendas del ropaje conceptual del liberalismo. Queda a criterio del lector si acaso es posible una desvinculación total de la filosofía política dominante al momento de diseñar soluciones sustentables en los multiculturales estados latinoamericanos.

»La Constitución Multicultural «, con su bagaje teórico, su crítica aguda y su argumentación razonable, es una obra de indispensable consulta para aquellos que pretendan conocer de qué modo la práctica constitucional puede brindar soluciones pacíficas para las cuestiones multiculturales dentro de los límites de un marco jurídico que al sensibilizarse con la diversidad, se vuelve inherentemente tenso y conflictivo. 